\title{
Tracking the time course of multidimensional stimulus discrimination: Analyses of viewing patterns and processing times during "same"_"different" decisions
}

\author{
Eva Belke \\ Department of Linguistics, University of Bielefeld, Germany \\ Antje S. Meyer
}

Behavioural Brain Sciences Centre, University of Birmingham, UK

\begin{abstract}
We investigated the time course of conjunctive "same"-_'different" judgements for visually presented object pairs by means of combined reaction time and on-line eye movement measurements. The analyses of viewing patterns, viewing times, and reaction times showed that participants engaged in a parallel self-terminating search for differences. In addition, the results obtained for objects differing in only one dimension suggest that processing times may depend on the relative codability of the stimulus dimensions. The results are reviewed in a broader framework in view of higher-order processes. We propose that overspecifications of colour, often found in object descriptions, may have an "early" visual rather than a "late" linguistic origin. In a parallel assessment of the detection materials, participants overspecified the objects' colour substantially more often than their size. We argue that referential overspecifications of colour are largely attributable to mechanisms of visual discrimination.
\end{abstract}

Discriminating objects in the outside world is a fundamental process for many higher-order processes. Referring to an object in the framework of similar context objects is closely tied to the detection of discriminative features. However, the visual and linguistic processes involved in such a "referential

Requests for reprints should be addressed to E. Belke, Graduate Program Task Oriented Communication, Faculty of Linguistics, University of Bielefeld, Universitätsstr. 25, 33615 Bielefeld, Germany. Email: ebelke@uni-bielefeld.de

This work is part of the research conducted in the graduate programme "Task Oriented Communication" at the University of Bielefeld, Germany, and was supported by the DFG (GRK 256/2). The research is part of a doctoral dissertation to be submitted by Eva Belke to the Faculty of Linguistics at the University of Bielefeld. We thank Hans-Jürgen Eikmeyer and Ulrich Schade for helpful comments and Martin Schmitz for technical support. 
communication task" (Piaget, 1926) have often been treated as separate phenomena. The evidence presented in this paper establishes a link between the empirical research in both areas.

We investigated the chronometry of the "same"-" different" decision for line drawings of simple objects of everyday relevance. The object pairs to be judged as "same", or "different" varied in colour, size, and/or object class, or were identical. We assessed the timing scheme of "same"-_different" judgements by measuring reaction times and tracking participants' eye movements during the decision process. To our knowledge, the time course of "same" "different" decisions has not yet been assessed by means of eye-tracking techniques. Eye movements reveal when and for how long objects or parts of a display are fixated. Although fixated objects are not necessarily attended to (Posner, 1980), fixation shifts (saccades) are always associated with shifts of visual attention (e.g., Deubel \& Schneider, 1996). During the 1990s, eye tracking has proved to be a useful tool to assess complex cognitive processes, such as speech production and reading (Meyer, Sleiderink, \& Levelt, 1998; Meyer \& van der Meulen, 2000; Rayner, 1998; Tanenhaus, Spivey-Knowlton, Eberhard, \& Sedivy, 1995; Zelinsky \& Sheinberg, 1997).

As previously indicated, the properties of multidimensional stimulus discrimination are of substantial interest in view of higher-order processes. Therefore, we will not only discuss the present findings in the empirical framework of multidimensional stimulus discrimination but also extrapolate from our data and the present state-of-the-art of research on "same"-" different" judgements to experiments on referential communication. In the experiments reviewed in this section, participants were asked to name multidimensional objects in the context of several other multidimensional objects. Referential overspecifications that are characteristic of object descriptions were predicted to occur for colour but not for size. Supportive evidence is provided by previous findings on referential communication and by a parallel assessment of the detection material by a naming task.

In the following, same and different are used to refer to the experimental conditions, i.e., the stimulus category of a given object pair. The notation "same" and "different" will be used for response types, i.e., for both potential response alternatives and actual responses made by subjects during the experiment (see Farell, 1985).

\section{“SAME"-_"DIFFERENT" JUDGEMENTS FOR MULTIDIMENSIONAL OBJECT PAIRS}

Since the pioneering work of Egeth (1966) on the visual perception of multidimensional stimuli, i.e., stimuli differing in more than one dimension, considerable effort has been devoted to establishing the processes underlying multidimensional stimulus discrimination (Allport, 1971; Bamber, 1969; 
Besner \& Coltheart, 1976; Bindra, Donderi, \& Nishisato, 1968; Donderi \& Case, 1970; Donderi \& Zelnicker, 1969; Hawkins, 1969; Jolicoeur \& Besner, 1987; Lindsay \& Lindsay, 1966; Miller, 1978; Miller \& Bauer, 1981; Nickerson, 1969, 1971, 1972; Sekuler \& Nash, 1972; Snodgrass \& Townsend, 1980; see also Farell, 1985, for a review). Much of the experimental work has been directed at testing models of the processes underlying "same" -"different" judgements for multidimensional stimuli. Classes of models have been defined using two basic parameters introduced by Egeth (1966): processing time (exhaustive vs self-terminating) and processing mode (serial vs parallel vs template matching). However, although there is extensive evidence on the visual perception of multidimensional stimuli, the findings seem to be rather inconsistent, especially with regard to the decision latencies for the basic stimulus conditions same and different (cf., Farell, 1985; Grill, 1971, for critical reviews). In evaluating the data, several factors must be considered: In most earlier experiments artificial stimuli were constructed to assess the predictions derived from specific models. Allport (1971) and Egeth (1966), for example, used geometrical shapes with inscribed numerals or tilts; Bamber (1969) used letter strings with identical or differing orthography; and Brunel and Ninio (1997) constructed their stimulus material of square lattices of black and white squares differing in single square positions (see also Grill, 1971, for a review). Although artificial and non-artificial stimuli have never been compared before, there are reasons to carefully distinguish them. When using objects, as we did in the present experiment, it must be considered that semantic and linguistic associations connected to their form can become activated even at a very early stage of visual processing (e.g., Boucart \& Humphreys, 1994). Thus, transferring experimental results from the artificial stimulus domain to the domain of line drawings of everyday objects may lead to a serious fallacy.

Beyond that, the "same"'-"different" experiments conducted before must be carefully inspected with regard to methodological differences, as the results obtained under different task conditions differ widely. The two basic methodological features are the timing of stimulus presentation (simultaneous vs sequential) and the task (disjunctive vs conjunctive judgements; see Farell, 1985). Taking into account methodological differences between experiments, however, the results can be re-evaluated and reduced to a few basic hypotheses on the structural and temporal properties of the decision process in a conjunctive "same" - "different" judgement:

Hypothesis 1. The search for differences in different object pairs is selfterminating, i.e., a decision is made as soon as any difference is detected (Bamber, 1969; Egeth, 1966; Farell, 1985; Hawkins, 1969; Snodgrass \& Townsend, 1980). The identity check on same object pairs, in contrast, is exhaustive. In conjunctive judgements, the overall reaction time to same stimuli includes a check of all 
dimensions and is usually longer than the reaction time to different stimuli (Downing, 1970; Downing \& Gossman, 1970; Egeth, 1966; Farell, 1985; Hawkins, 1969).

In some studies, however, "same" answers were found to be faster than “different" answers (cf., Bamber, 1969; Downing, 1970; Entus \& Bindra, 1970; Farell, 1985; Grill, 1971; Hawkins, 1969; Nickerson, 1965, 1967). It turned out that this fast-"same" phenomenon occurred in experiments with specific methodological features in the sense of the earlier classification (cf., Farell, 1985). Further investigations revealed that, for multidimensional conjunctive judgements, "'same' judgments are faster than the slowest class of 'different' judgments (for which a single dimension is critical)" (Farell, 1985, p. 423). This pattern, in turn, could be explained on the basis of the inherent properties of the dimensions involved. The degree of codability of the dimensions appeared to be particularly influential (Bindra et al., 1968; Farell, 1985): According to a definition offered by Bindra et al., codability "refers to the property of a stimulus that enables most Ss to categorize it in absolute terms, without reference to another (e.g., standard) stimulus. ... By this definition, stimuli such as colors ... are codable, and stimuli such as ... line length are noncodable" (p. 129). The effects of codability can thus be summarised as follows:

Hypothesis 2. There is a codability effect for the detection of the difference dimensions in different stimuli (Bindra et al., 1968; Farell, 1985): Relative stimuli are processed substantially more slowly than absolute dimensions. The notion of codability can explain both the relation among processing times for different conditions and the relation between the different conditions and the same condition.

Hypothesis 3 . The dimensions to be judged in a conjunctive search can be processed in parallel. Detection times for differences in less codable, relative dimensions are longer than reaction times to same stimuli, which suggests that the exhaustive check of all dimensions for giving a "same" answer is accomplished in a parallel way (see Farell, 1985).

Note, however, that being codable or non-codable is an inherent property of a dimension, whereas the discriminability of difference conditions is part of the experimental manipulation (see also Bindra et al., 1968). Nevertheless, codability is often confounded by discriminability: Size, for example, as-by definition-non-codable dimension, can be more or less discriminable. We will therefore not consider the notion of codability as a binary distinction between codable and non-codable dimensions but as a continuum between highly codable classes of dimensions (absolute dimensions) and less codable classes of dimensions (relative dimensions). 
In the present study, we wanted to replicate the findings listed previously with non-artificial stimuli on the basis of line drawings of real objects. Different stimulus pairs varied in terms of object class, ${ }^{1}$ and/or colour, and/or size. With these dimensions, we were able to draw a within-subjects comparison of the processing differences between highly codable absolute features (object class and colour) and less codable relative features (size) and between form (size, object class) and colour features (cf., Garner \& Felfoldy, 1970; Santee \& Egeth, 1980; Watanabe, 1988b). Note that we deliberately chose a low ratio for the size dimension (5:4). If the ratio is very high (say 50:1), the small and large stimuli can easily be identified on the basis of their absolute sizes, and size ceases to be a relative dimension. Bundesen and Larsen (1975) and Larsen and Bundesen (1978) showed that the detection times for size differences got shorter with increasing size ratios, which shows that choosing more discriminable size ratios makes the size dimension more codable, if not even absolute. The correlation of codability and discriminability is ubiquitous and has to be taken into account when effects of codability are considered.

As already indicated, eye movements provide insight into the processing of a stimulus display prior to an overt response. We predicted that differences between viewing patterns should be positively correlated with differences in processing times. Reaction times should increase with increasing viewing times. The following specific predictions were derived for the decision process in a conjunctive "same"-“"different'” judgement.

Effects of the basic response categories "same" vs "different". Previous experiments on "same"-“different" judgements have provided substantial evidence that the parallel processing mode and the degree of codability have a strong impact on the relation between processing times for same and different types of different stimuli (Bindra et al., 1968; Farell, 1985). Therefore, we predicted that stimuli differing in colour or object class as absolute and highly codable dimensions should be associated with faster processing times than same stimuli. Similarly, the complexity of the viewing patterns, i.e., the number of glances at the objects and the number of regressions to an object viewed before, should increase for same stimuli. Size, on the contrary, being a less codable relative dimension, should be associated with slower reaction times and more complex viewing patterns than same stimuli.

\footnotetext{
${ }^{1}$ The term object class is derived from the logical sense of the term class and should be distinguished from the semantically based notion of a category. Whereas the term semantic category is used to refer to a group of objects sharing certain semantic attributes, the term object class, in this paper, refers to a cluster of variations of one object only. The members of the respective classes are basically identical except for differences in inherent dimensions like colour or size. The object class of cap, for example, might contain elements like a large red cap, a small red cap, a blue and a green cap, but no other object except for a cap.
} 
Effects of the number of differences involved in different stimuli. On the basis of findings on self-terminating search effects in conjunctive "same", “different" judgements (Bamber, 1969; Egeth, 1966; Farell, 1985; Hawkins, 1969; Snodgrass \& Townsend, 1980), we predicted that the detection times in a two- or three-dimensional difference condition should be determined by the fastest reaction time to any of the single dimensions involved. Usually this will be the dimension yielding the shortest reaction time in a one-dimensional difference condition. Similarly, the difference dimension that is easiest to detect should determine the viewing patterns and viewing times for multidimensional differences.

Effects of different types of differences. For one-dimensional differences, we predicted an effect of codability on the eye-movement patterns. Differences in relative features, such as size, should be associated with complex viewing patterns and glances to and from both stimuli, because the difference must be computed by means of a reference system that identifies one object as being smaller or bigger than the other. In contrast, in the case of a difference in an absolute dimension, such as colour, the "same"-_"different" decision can be drawn by first retaining the structural description of the first object and then comparing the memorised information with that extracted from the second object (cf., Carlson-Radvansky \& Irwin, 1995). This strategy should be associated with rather simple viewing patterns. According to Boucart and Humphreys (1992, 1994, 1997), the processing times for form differences are longer than those for colour differences. Therefore, the processing times for object class differences should be longer than those for colour differences. As outlined earlier, the detection of the multidimensional difference conditions should be determined by the dimension with the highest degree of codability (self-terminating search).

Closely connected to the analysis of reaction times to multidimensional differences is the empirical validity of models incorporating serial vs parallel processing modes. As outlined previously, experimental findings on "same" vs "different" decision times support parallel models because "same" answers for identical stimuli can be given faster than "different" answers for difference dimensions of low codability (Farell, 1985). For the present experiment we therefore expected the processing times for identical stimulus pairs to be faster than those for stimulus pairs differing in size. However, although all dimensions are processed in parallel, identical stimuli have to be checked exhaustively with regard to all dimensions, whereas "different" answers can be based on a selfterminating search. Therefore, we predicted faster reaction times to different stimuli differing in absolute and highly codable dimensions such as colour or object class than to same stimuli. 


\section{METHOD}

\section{Participants}

Twelve female and five male students of the University of Bielefeld took part in the experiment. They were all right-handed. The experiment took about 40 minutes and each participant was paid DM 8.

\section{Stimuli}

108 pairs of stimuli were created from combinations of the dimensions object class, colour, and size. Based on German category norms (Mannhaupt, 1983), typical representatives of three categories (animals, household furniture, clothing) were selected to form the three levels of the dimension object class (Katze [cat], Lampe [lamp], Hose [trousers]). The objects were semantically and visually dissimilar and were matched in terms of grammatical gender, number of syllables of their names, and concreteness. Line drawings for each object were taken from the Snodgrass and Vanderwart collection (1980). Nine copies of each object were prepared varying in colour (red, blue, yellow) and size (small, medium, large), resulting in 27 multidimensional objects.

By combining the objects to pairs, 54 same and 54 different pairs were created. The group of different object pairs was composed of three subsets of 18 pairs each, containing items with one-, two-, and three-dimensional differences, respectively. The groups of one- and two-dimensional differences each consisted of three sub-groups with six pairs each. In sum, there were seven groups of difference types, namely colour $(\mathrm{C})$, object class $(\mathrm{O})$, and size $(\mathrm{S})$ in the onedimensional group (three sets of six pairs each), colour and size (CS), colour and object class (CO), and size and object class (SO) in the two-dimensional group (three sets of six pairs), and the group of stimulus pairs varying in all three dimensions (CSO; one set of 18 pairs). Object pairs differing in size were created by combining medium-sized target objects with large and small context objects in equal shares. When two objects of a pair did not differ in size, they were both medium-sized. The ratio between the sizes of two objects differing in size was always 5:4, i.e., the same ratio was applied for large and medium objects (1.25:1) and medium and small objects (1:0.8). The objects were scaled to fit into a frame of $3.01^{\circ} \times 3.14^{\circ}$ (medium), $3.77^{\circ} \times 3.94^{\circ}$ (large), and $2.41^{\circ} \times$ $2.51^{\circ}$ (small) with a mean distance from the screen of $60 \mathrm{~cm}$.

For the analysis of the eye movements we needed to find a measurable criterion to identify the point in time when the decision had been taken and the button press was initiated. We therefore positioned the two objects used for the decision task at the top left and right corners of the display and added a small symbol at the bottom. Participants were instructed first to carry out 
the decision task on the two objects at the top of the screen and to then decide whether the symbol at the bottom was a plus or a cross. The answers were given verbally by saying "Plus" when they saw a plus and saying nothing whenever there was a cross. We chose different answer modalities for the two tasks to minimise interference effects. Participants were asked to do the two tasks one after the other as quickly as possible. This should force them not to stick to the first task until the end of the motor reaction but to start with the second task as soon as the decision on the first task was drawn. Proportionally distributed among the conditions, one-sixth of all object pairs were combined with a plus; the rest were combined with a cross. The plus/cross symbol was centred at the bottom of the screen. The two objects were positioned in the upper corners of the screen at a distance of $2.52^{\circ}$ from the borders of the screen and $7.81^{\circ}$ from each other.

Although, in the case of a display with only two objects, a differentiation between target and context object seems superfluous, there were several reasons to maintain this distinction for the present experiment: To control for effects of preferred scanning patterns, two items were constructed of each stimulus pair. In one item the target object was displayed in the upper left and the context object in the upper right corner, and in the other item the positions of the objects were switched. The stimulus set thus consisted of 216 items. The target object was always the object that the participants' first gaze was guided to by means of a fixation point presented immediately before the stimulus display at the target position. In order to implement size as a relative dimension, the target object was always assigned to a medium-sized level so that its relative size could be varied by choosing either a smaller or a bigger context object.

\section{Design}

The experiment consisted of three nested within-subjects factors, namely $R$ type (two levels) with the correct response types "same", and "different", $D$ number (three levels) with the number of differences involved in different object pairs, and D-type (seven levels). The levels corresponded to the difference types described earlier. The items were assigned proportionally to six blocks with each block consisting of 18 same and 18 different stimulus pairs. The different pairs of a block included one item of each of the one- and twodimensional conditions and three items of the three-dimensional condition. In all blocks, one-sixth of the same and different stimulus pairs were combined with a plus, the rest with a cross. In half of the same stimulus pairs and half of the different stimulus pairs of each block the fixation point and the target object were positioned on the left and the context object on the right; in the remaining stimuli the positions of target and context object were reversed. The order of experimental blocks was randomised. Within each block the 
items were pseudo-randomised for each subject. Successive items never contained identical stimuli. ${ }^{2}$

\section{Apparatus}

The experiment was controlled by a Compaq Pentium 4000 computer. The items were presented on a Sony Trinitron 20-inch monitor. Reaction times were registered with a two-button pushbutton panel. Via an SMI HW-EyeLink-HM eye-tracking system participants' eye movements were monitored with a sampling rate of $250 \mathrm{~Hz}$. Onset and offset times and coordinates of all fixations were extracted from the data recorded by the eye tracker.

\section{Procedure}

Prior to the experiment, participants received written instructions on the two decision tasks (same/different, plus/cross), and on the function of the fixation point. They were asked to do each task as fast and as accurately as possible. Then the headband of the eye tracker was mounted and the system was calibrated. A set of nine same and nine different trials of all types and numbers was included in a practice block preceding the experimental blocks. All participants first practised the sequential execution of the two tasks and got used to the display and the assignment of response categories to the two buttons. On the first $1000 \mathrm{~ms}$ of each trial a fixation point was presented in the upper left or right corner of the screen depending on the position of the upcoming starting object. Immediately following, the two stimulus items were presented together with the symbol at the bottom of the screen for $3200 \mathrm{~ms}$. Reaction times were measured from the onset of the stimulus display until a button was pressed. Reactions to the "same" -"different" decision task that took longer than $1800 \mathrm{~ms}$ were registered as time-outs. During each trial eye movements were recorded. The verbal reactions to the plus/cross decision task were monitored during the experiment but were not analysed any further.

\section{Analysis}

Distinct stimulus areas within the display were defined in pixels, resulting in one stimulus area each for the upper left corner, for the upper right corner and for the symbol at the bottom of the screen. All fixations lying inside the contours of an object or less than $1.25^{\circ}$ away from it were scored as object fixations. In addition, we defined a fixation area positioned between the two stimuli as this

\footnotetext{
${ }^{2}$ This allows for the possibility that two items of the same or the different condition may follow each other. However, results of previous experiments (Krueger, 1973; Nickerson, 1973; Williams, 1972) suggest that the effects of the immediacy of individual stimulus elements are even stronger than those of the recency of response types. Therefore, we randomised the items with regard to the stimuli occurring within the items rather than to the conditions they belong to.
} 
area might be of special importance during the comparison of the objects. For each stimulus area all fixations were extracted and onset and offset of the fixations, their durations and their coordinates were registered. The onset times of fixations starting before and ending after stimulus onset were recoded by zero. Depending on the position of the target object, fixations on the two objects were coded as target and context object fixations respectively. When participants had turned away from an object, the viewing duration of the current fixation block was computed as the difference between the offset of the last fixation and the onset of the first fixation on the object. Such blocks of consecutive fixations on an object will be termed "gazes" and their duration "gaze duration". Note that this definition of gaze duration differs from that used by Just and Carpenter (1980; see also Henderson, Pollatsek, \& Rayner, 1987, 1989), who did not include the duration of the saccades within a fixation block in their computation of gaze duration. Viewing patterns were defined on the basis of the order of gazes on the target object (T), the context object (C), the symbol at the bottom of the screen $(\times)$, and the intermediate region between the two objects (B).

Statistical analyses were run over both subjects and items as random factors. An item was defined as one instantiation of a difference type, i.e., each of the 216 stimulus displays was regarded as an item. We will report $F 1$-statistics (using subject variation) and $F 2$-statistics (using item variation). It is possible to obtain significant results in separate $F 1$ and $F 2$ statistics but a non-significant $F$ value in an ANOVA including both subject and item variance (Clark, 1973; Raaijmakers, Schrijnemakers, \& Gremmen, 1999). We therefore computed $F_{\text {min }}$-values based on the $F 1$ - and $F 2$-statistics. All significant results presented below yielded significant $F_{\min }$-statistics.

\section{RESULTS}

\section{Error analysis}

The data from 88 trials $(2.4 \%)$ were discarded because participants pressed the wrong button ( 21 trials, $0.6 \%$ ) or did not react in time (67 time-outs, $1.8 \%$ ). The analysis of the error rates revealed neither significant effects of the factors Rtype, D-number, nor D-type. Error rates were not systematically related to the viewing patterns.

\section{Analysis of viewing patterns}

The analysis of viewing patterns was restricted to trials with valid reaction times. Viewing patterns starting from the context object (266 trials $=7.7 \%$ ), from the symbol at the bottom of the screen ( 6 trials $=0.2 \%)$ or from the intermediate area between the two objects $(151$ trials $=4.4 \%)$ were discarded from the analysis. The remaining valid viewing patterns starting from the target 
object (3026 trials $=87.7 \%$ ) mainly consisted of viewing patterns with fixations on the target object and the context object $(\mathrm{T}-\mathrm{C}-\times: 1936$ trials $=56.1 \%$, T-C-T$\times: 701$ trials $=20.3 \%$, T-C-T-C $-\times: 83$ trials $=2.4 \%)$. A total of 306 trials $(8.9 \%)$ were associated with a direct viewing pattern $(\mathrm{T}-\times)$, i.e., only the target object, but not the context object was fixated before the gaze was shifted to the symbol at the bottom of the screen. The intermediate region between target and context object turned out to be of minor importance, as the registered fixations were almost exclusively single fixations of short duration that occurred during the subject's change of gaze from one object to the other. They were not included in the analysis of viewing patterns, but were taken into account in the analysis of viewing times (see later).

We classified the viewing patterns with regard to the complexity of the exploration into simple vs complex patterns. All patterns with at least one gaze at each object were classified as complex viewing patterns. The complex patterns were further classified according to their extensiveness into patterns without regressions $(\mathrm{T}-\mathrm{C}-\mathrm{X})$ and patterns with regressions to an object fixated before (T$\mathrm{C}-T-\times$ and $\mathrm{T}-\mathrm{C}-T-C-\times$, respectively).

Table 1 summarises the relative frequencies of all pattern types. As Table 2 shows, the analysis of the complexity and the extensiveness of the viewing patterns revealed significant effects of the factors R-type, D-number, and D-type

TABLE 1

Percentages of viewing patterns of different complexity and extensiveness, broken down by the factors R-type, D-number, and D-type

\begin{tabular}{|c|c|c|c|c|}
\hline & \multicolumn{4}{|c|}{ Viewing patterns } \\
\hline & \multicolumn{2}{|c|}{ Complexity } & \multicolumn{2}{|c|}{ Extensiveness } \\
\hline & Simple & Complex & $\begin{array}{c}\text { No } \\
\text { regressions }\end{array}$ & $\begin{array}{l}\text { One/two } \\
\text { regressions }\end{array}$ \\
\hline \multicolumn{5}{|l|}{ R-type } \\
\hline Same & 5.3 & 94.7 & 63.0 & 37.0 \\
\hline Different & 15.3 & 84.7 & 80.2 & 19.8 \\
\hline \multicolumn{5}{|l|}{ D-number/D-type } \\
\hline 1-dimensional differences & 9.2 & 90.8 & 68.5 & 31.5 \\
\hline $\mathrm{C}$ & 13.3 & 86.7 & 80.0 & 20.0 \\
\hline $\mathrm{S}$ & 2.2 & 97.8 & 46.6 & 53.4 \\
\hline $\mathrm{O}$ & 12.9 & 12.9 & 84.4 & 15.6 \\
\hline 2-dimensional differences & 15.2 & 84.8 & 86.5 & 13.5 \\
\hline $\mathrm{CO}$ & 18.9 & 81.1 & 86.5 & 13.5 \\
\hline $\mathrm{CS}$ & 11.0 & 89.0 & 84.3 & 15.7 \\
\hline SO & 15.7 & 84.3 & 89.0 & 11.0 \\
\hline 3-dimensional differences & 21.8 & 89.2 & 87.2 & 12.8 \\
\hline $\mathrm{CSO}$ & 21.8 & 89.2 & 87.2 & 12.8 \\
\hline
\end{tabular}


TABLE 2

ANOVA results on the effects R-type, D-number, and D-type on the complexity (simple vs complex) and extensiveness (no regressions vs one or more regressions) of the viewing patterns

\begin{tabular}{|c|c|c|c|c|}
\hline & \multicolumn{2}{|c|}{ Subjects } & \multicolumn{2}{|c|}{ Items } \\
\hline & $d f$ & $F 1$ & $d f$ & $F 2$ \\
\hline \multicolumn{5}{|l|}{ Complexity $^{\mathrm{a}}$} \\
\hline R-type & 1,16 & $15.01 * *$ & 1,214 & $6.27 * * *$ \\
\hline D-number & 2,32 & $8.61 * *$ & 2,106 & $7.56^{* *}$ \\
\hline D-type ${ }^{c}$ & 6,96 & $6.80 * * *$ & 6,102 & $7.15^{* * *}$ \\
\hline D-type ${ }^{d}$ & 2,32 & $12.12 * * *$ & $2, \quad 33$ & $7.08^{* *}$ \\
\hline \multicolumn{5}{|c|}{ Extensiveness ${ }^{\mathrm{b}}$} \\
\hline R-type & 1,16 & $17.60 * *$ & 1,214 & $17.72 * * *$ \\
\hline D-number & 2,32 & $8.18^{* *}$ & 2,106 & $7.93 * *$ \\
\hline$D-$ type $^{c}$ & 6,96 & $21.31 * * *$ & 6,102 & $39.34 * * *$ \\
\hline D-type ${ }^{d}$ & 2,32 & $16.23 * * *$ & $2, \quad 33$ & $10.29 * * *$ \\
\hline
\end{tabular}

\footnotetext{
${ }^{\mathrm{a}}$ The analyses are based on the relative frequencies of complex viewing patterns observed for each subject/item and each respective condition.

${ }^{\mathrm{b}}$ The analyses of extensiveness are based on the relative frequencies of viewing patterns without regressions observed for each subject/item under the respective conditions.

${ }^{c}$ Overall effect of the factor D-type.

${ }^{\mathrm{d}}$ Effect of the factor D-type within the group of one-dimensional differences. $* * p<.01 ; * * * p<.001$.
}

on the viewing patterns. The proportion of complex patterns and of patterns with regressions was significantly larger under the same than under the different condition (cf., Tables 1 and 2). Participants obviously compared the two objects more thoroughly when making a "same" decision. These results are in line with the predicted effects of self-terminating search: To make a "same" decision, subjects have to check both objects exhaustively, i.e., with regard to all dimensions. In contrast, a "different"' decision can be based on any difference that is detected. The observed proportions of viewing patterns under the two- and three-dimensional conditions correspond to those observed under the colour and object class condition in the one-dimensional group, i.e., participants obviously used the dimensions that were easiest to detect to make a "different" response (cf., Table 1). Analyses of the factor D-type for the sub-groups of one-, two-, and three-dimensional differences showed significant effects for the group of onedimensional differences only. Size was associated with significantly more complex viewing patterns than colour or object class. The latter conditions, in turn, did not differ from each other. With regard to the groups of two- and threedimensional differences there were no significant differences (see Table 1).

In sum, the results of the analysis of viewing patterns support our main hypotheses. Corresponding to exhaustive as opposed to self-terminating search 
strategies for same vs different stimuli, the viewing patterns under the same condition were significantly more complex than those under the different condition. Within the different condition differences in size as a relative feature were associated with significantly more regressions than differences in the more codable features object class and colour. Recall, however, that this effect of codability may be confounded with effects of discriminability. The comparison of viewing patterns between the difference types with one as opposed to two or more difference dimensions provides evidence for a self-terminating search strategy: In the conditions with two- or three-dimensional difference types, the frequencies of simple viewing patterns and of patterns without regressions were nearly identical to those registered under the easily codable one-dimensional difference types (colour and object class). This seems to be due to the easy detection of colour and object class differences, which can be processed faster than differences in size. Obviously size, being part of the SC, SO, and SCO conditions, was not processed after the detection of a difference in colour or object class as it did not influence the viewing patterns under these conditions in any way.

\section{Analysis of viewing times and reaction times}

In order to conduct analyses of the viewing times, we defined the following parameters:

- VT(T): viewing time of the target object, defined as sum of the duration of the first gaze and all regressions.

- VT(C): viewing time of the target object, defined as sum of the duration of the first gaze and all regressions. This was zero for direct viewing patterns without gazes at the context object.

- VTtot: VT(T) + VT(C) + VT(B); fixations on the area between target and context object (B) were included if they occurred prior to the first fixation on the plus/cross. ${ }^{3}$

For each dependent variable, processing times within a given condition that deviated by more than two standard deviations from the respective participant's and item's mean were replaced by estimates following the procedure recommended by Winer (1971). The proportion of replaced values was below $5 \%$ for all variables. Figure 1 displays the results for the same condition and all different conditions.

As outlined previously, only the viewing times preceding the first fixations on the icon at the bottom of the screen were evaluated. The similarity of the results obtained for reaction times and total viewing times (dashed lines in

\footnotetext{
${ }^{3}$ As previously indicated, the fixations registered in this area (B) were mostly single fixations of short durations that occurred during the subject's change of gaze from one object to the other. This is why VTtot approximates the sum of VT(T) plus VT(C) in most cases.
} 


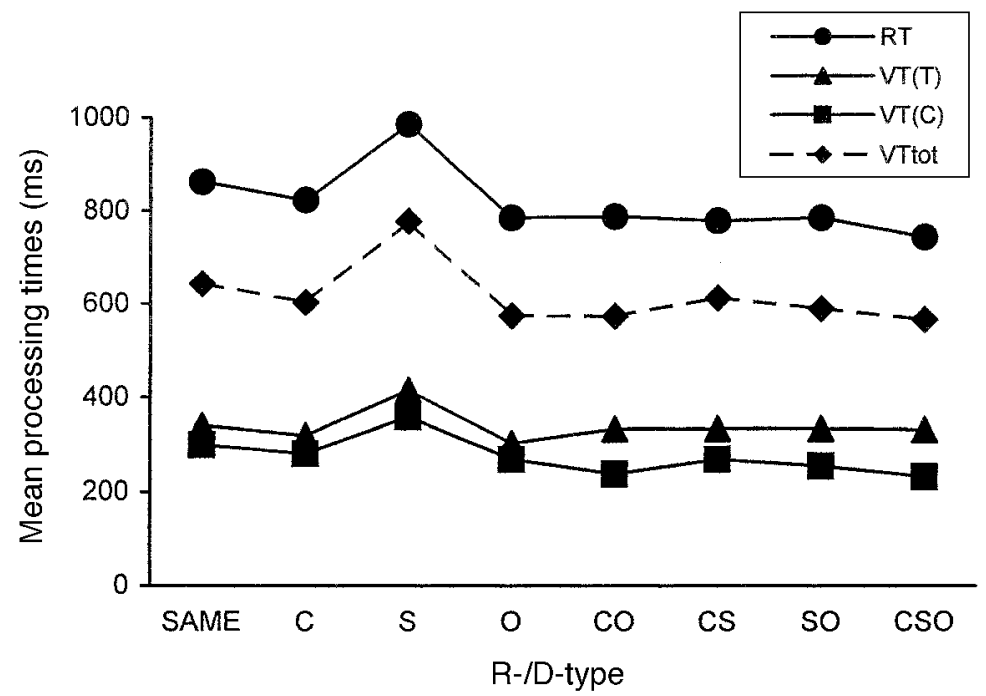

Figure 1. Mean values for RT, VTot, VT(T), and VT(C), displayed for the same condition and each of the different conditions. Dashed lines for VTtot indicate that VTtot is no direct measure of processing time but represents the sum of VT(T) and VT(C).

Figure 1) can be regarded as an index of the high validity of total viewing times as an indicator for the processing time for the objects. Recall that we had included the second task to be able to differentiate between overall processing times (measured as total viewing times) and reaction times (measured as the moment of the button press). In an ANOVA over the difference between total viewing times and reaction times including all different conditions and the same condition we obtained no significant effects of difference type. The time period between total viewing time and reaction time can thus be interpreted as motor latency.

Effects of R-type. As Table 3 shows, participants reacted significantly faster to different than to same object pairs, $F 1(1,16)=10.97, p<.01 ; F 2(1,214)=$ 23.58, $p<.01$. The total time taken to explore the whole display was significantly shorter for different than for same object pairs, $F 1(1,16)=10.24 ; \mathrm{p}$ $<.01 ; F 2(1,214)=16.11, p<.01$. Looking at the viewing times of the target and the context objects separately, the effect of the factor R-type reached significance only for the context object, $F 1(1,16)=16.39, p<.01 ; F 2(1,214)$ $=20.78, p<.01$, but not for the target object (both $F_{\mathrm{s}}<1$ ).

These results are in line with the findings on the exploration patterns for same vs different object pairs, showing fewer simple viewing patterns for the same than for the different condition. Subjects are faster in judging two objects as 
TABLE 3

Mean processing times and standard deviations by subjects for each response type

\begin{tabular}{lrrrc}
\hline & $R T$ & $V T(T)$ & $V T(C)$ & $V T$ tot \\
\hline Same & & & & \\
$M$ & 863 & 340 & 299 & 644 \\
SD & 142 & 64 & 67 & 111 \\
Different & & & & \\
$M$ & 800 & 337 & 264 & 605 \\
SD & 142 & 84 & 81 & 129 \\
\hline
\end{tabular}

being different than they are in judging two objects as being identical, because for a different decision they do not have to scan both objects exhaustively with regard to all dimensions but can make a decision as soon as they have found a difference. Because of the larger proportion of simple patterns under the different condition, the context object was looked at less often than under the same condition, yielding shorter mean viewing times of the context object. We had expected to find a similar effect of the smaller number of regressions under the different condition on the viewing times of the target object. Contrary to our prediction, however, the extensiveness of the viewing patterns was not directly correlated to the viewing times of the objects in the display. We will further discuss this finding in the sub-section on "Structural differences between viewing patterns",.

Effects of D-number. The factor D-number exhibited significant effects on all dependent variables, except the viewing times of the target object, $F 1(2,32)$ $>16, p<.001 ; F 2(2,106)>7, p<.01$ for RT, VT(C), and VTtot. As Table 4 shows, reaction times and viewing times were significantly shorter for one- than for two- and three-dimensional differences. Paired comparisons revealed significant differences between the processing times of one- and twodimensional difference types, $t 1(16)>4.6, p<.001 ; t 2(71)>2.5, p<.01$ for $\mathrm{RT}, \mathrm{VT}(\mathrm{C})$, and VTtot, and of one- and three-dimensional difference types, $t 1(16)>5.9, p<.001 ; t 2(71)>3.4, p<.001$ for RT, VT(C), and VTtot. Twoand three-dimensional difference conditions did not differ significantly. This finding supports the notion of a self-terminating search strategy in visual discrimination. The detection times of multidimensional differences appeared to be determined by an easily detectable dimension and were independent of the number of differences involved (cf., Table 4).

We had predicted that the differences between viewing patterns in terms of complexity and extensiveness should be related to differences in processing times. The relative complexity of the observed viewing patterns was correlated 
TABLE 4

Mean processing times and standard deviations by subjects for one-, two-, and three-dimensional difference types

\begin{tabular}{lrrrr}
\hline & $R T$ & $V T(T)$ & $V T(C)$ & VTtot \\
\hline 1-dimensional differences & & & & \\
$\quad M$ & 868 & 348 & 305 & 656 \\
SD & 146 & 73 & 75 & 125 \\
2-dimensional differences & & & & \\
$M$ & 785 & 332 & 254 & 592 \\
SD & 145 & 91 & 84 & 135 \\
3-dimensional differences & & & & \\
$M$ & 745 & 331 & 232 & 567 \\
SD & 136 & 99 & 101 & 139 \\
\hline
\end{tabular}

with the viewing times of the context object (see earlier), but there were no effects of the relative extensiveness of the patterns on the viewing times of the target object. We assume that this might be due to differences between the individual duration of single gazes within a complex sequence of gazes at both objects (see later sub-section "Structural differences between viewing patterns"').

Effects of D-type. The main effect of the factor D-type was significant for RT, VT(T), VT(C), and VTtot, F1(6,96)> 7.7, $p<.001 ; F 2(6,102)>5.7, p<$ .001 for all variables. As Table 5 and Figure 1 show, the processing times for size differences were slower than for all other difference types. The remaining difference types did not differ substantially from each other. We conducted separate analyses of variance for three groups of difference types, namely the group of one-dimensional differences $(\mathrm{S}, \mathrm{C}, \mathrm{O})$, the two-dimensional differences ( $\mathrm{CO}, \mathrm{CS}, \mathrm{SO})$, and finally the group of more-than-one-dimensional differences, consisting of the difference types $\mathrm{CO}, \mathrm{CS}, \mathrm{SO}, \mathrm{CSO}$. As we had expected given the self-terminating search effect reported previously, we did not obtain any significant results with regard to the two last-mentioned groups, but only for the group of one-dimensional differences, $F 1(2,32)>11.8, p<.001 ; F 2(2,34)>$ 6.2. $p<.001$ for RT, VT(T), VT(C), and VTtot.

Within the group of one-dimensional differences the predicted effects of the different degrees of codability of absolute and relative dimensions were confirmed: Size was processed significantly more slowly than colour, $t 1(16)>4.7$, $p<.001 ; t 2(32)>2.5, p<.01$ for all variables, and object class, $t 1(16)>3.9, p<$ $.01 ; t 2(32)>3.3, p<.01$ for all variables. Contrary to our initial expectations, colour and object class did not differ significantly from each other (cf., Table 5). For the "same"-" "different"' decision process, the absoluteness of a dimension seemed to be more crucial than the colour vs form aspect. Dunnet tests $(p<.05)$, 
TABLE 5

Mean processing times and standard deviations

by subjects for each difference type

\begin{tabular}{|c|c|c|c|c|}
\hline & $R T$ & $V T(T)$ & $V T(C)$ & VTtot \\
\hline \multicolumn{5}{|l|}{$\mathrm{C}$} \\
\hline$M$ & 824 & 319 & 280 & 603 \\
\hline SD & 154 & 75 & 80 & 135 \\
\hline \multicolumn{5}{|l|}{$\mathrm{S}$} \\
\hline$M$ & 986 & 415 & 359 & 779 \\
\hline SD & 190 & 79 & 73 & 131 \\
\hline \multicolumn{5}{|l|}{$\mathrm{O}$} \\
\hline$M$ & 786 & 303 & 269 & 575 \\
\hline SD & 139 & 95 & 110 & 151 \\
\hline \multicolumn{5}{|l|}{$\mathrm{CO}$} \\
\hline$M$ & 789 & 333 & 237 & 574 \\
\hline SD & 185 & 95 & 107 & 120 \\
\hline \multicolumn{5}{|l|}{ CS } \\
\hline$M$ & 780 & 334 & 269 & 613 \\
\hline $\mathrm{SD}$ & 133 & 76 & 80 & 134 \\
\hline \multicolumn{5}{|l|}{ SO } \\
\hline$M$ & 786 & 334 & 254 & 590 \\
\hline SD & 148 & 126 & 102 & 167 \\
\hline \multicolumn{5}{|l|}{$\mathrm{CSO}$} \\
\hline$M$ & 745 & 331 & 232 & 567 \\
\hline SD & 136 & 99 & 101 & 139 \\
\hline
\end{tabular}

conducted to determine the relation between the individual one-dimensional difference conditions and the two- and three-dimensional conditions, revealed significant differences between size and the multidimensional conditions only. All multidimensional differences were processed as fast as one-dimensional colour or object class differences.

In sum, these results clearly confirm the assumption of a self-terminating search strategy based upon a codability effect. Colour and object class as absolute dimensions were processed significantly faster than size as a relative dimension and they therefore determined the processing times for multidimensional differences. Effects of colour vs form processing did not influence processing times of colour and object class differences in the way we had hypothesised (cf., Boucart \& Humphreys, 1992, 1994, 1997). What seems to determine the reaction time to a difference in object class is the absoluteness of the object class dimension but not the fact that it is a form dimension.

Additional analyses of the effects of codability. As outlined at the beginning, Bindra et al. (1968) introduced the notion of codability in order to explain the inhomogeneous pattern of results for same vs different stimuli and 
the fast-"same" phenomenon. They showed that the observed discrepancies were due to the fact that same stimuli were processed more slowly than stimuli differing in absolute dimensions but faster than stimuli differing in relative dimensions. In line with Bindra et al., we found significantly slower processing times for stimulus pairs differing in size than for identical stimulus pairs, Dunnet tests, $p<.05$ for RT, VT(T), VT(C), VTtot (see also Figure 1). In the remaining comparisons (same vs $\mathrm{C} / \mathrm{O} / \mathrm{CO} / \mathrm{CS} / \mathrm{SO} / \mathrm{SCO}$ ), the "same" processing times were slower than the respective "different" processing times. For RTs, Dunnet tests $(p<.05)$ revealed significant differences between the same condition and each of the remaining stimulus conditions except for colour (O, CO, CS, SO, $\mathrm{CSO})$. The analyses of VT(C) and VTtot showed significant differences between same and $\mathrm{CO}$ and same and CSO only. For the viewing times of the target object we obtained no significant differences between the same condition and the remaining difference types. These findings are in line with a parallel processing mode (Allport, 1971; Bamber, 1969; Bindra et al., 1968; Donderi \& Case, 1970; Donderi \& Zelnicker, 1969; Downing \& Gossman, 1970; Egeth, 1966; Hawkins, 1969): If the identity check of all dimensions for a "same" decision had been conducted in a serial manner, the processing times would have been even longer than those for a "different" decision in size-discrepant shapes.

Structural differences between viewing patterns. We had predicted that qualitative differences between viewing patterns in terms of complexity and extensiveness should be related to quantitative differences in viewing times for target and context object. We obtained significant effects of the factors R-type and D-number on both the complexity and the extensiveness of the viewing patterns. As predicted, $\mathrm{VT}(\mathrm{C})$ correlated with the complexity of the viewing patterns: The more direct viewing patterns were observed, the shorter were the viewing times of the context object (see previously). However, the viewing times of the target object were not related to the relative extensiveness of the observed viewing patterns: Viewing patterns with a regression to the target object yielded similar $\mathrm{VT}(\mathrm{T})$ as viewing patterns without regressions to the target object. This might be due to structural differences between the viewing patterns: Each pattern may be associated with different ways of extracting information and memorising parts of the display in visual short-term memory (cf., Carlson-Radvansky \& Irwin, 1995; Coltheart, 1980; Irwin, 1991, 1992; Zelinsky \& Sheinberg, 1995, 1997). In the analyses described earlier, the viewing time of an object was defined as the sum of the first gaze at the object and all regressions to it. However, in view of structural differences within viewing patterns, analyses of individual gaze durations should be a more appropriate approach to the structural and temporal differences between viewing patterns. We assumed that more complex viewing patterns were associated with shorter gaze durations for the target object, whereas viewing patterns of less complexity should be associated with longer gaze durations. 
In our test of this hypothesis, we could only include the first gaze at the target object-VT1(T) in the following - because for simple patterns we did not have any data on gaze durations for the context object. We compared simple and complex viewing patterns with and without regressions with respect to VT1(T). In addition, we compared total viewing times, overall reaction times, and viewing times of the target object between pattern types. The total viewing time for simple viewing patterns was computed on the basis of the former definition of viewing times with $\mathrm{VT}(\mathrm{C})=0$ and $\mathrm{VTtot}=\mathrm{VT}(\mathrm{T})$. The main types of viewing patterns (simple patterns, complex patterns with/without regressions) were coded as levels of the factor pattern (3), which was analysed in analyses of variance over each of the dependent variables VT1(T), VT(T), VTtot, and RT. Except for one subject, who never applied the simple viewing pattern, all subjects could be included in the analysis of the respective patterns. For the item analysis we had to exclude 81 items that were associated with only two of the three patterns.

The main effect of the factor pattern was significant for each of the variables defined previously, $F 1(2,30)>16, p<.001 ; F 2(2,270)>17, p<.001$ for VT1(T), VT(T), VTtot, and RT. However, its influence on the respective variables differed (see Table 6), as illustrated in Figure 2.

The duration of the first gaze at the target object, VT1(T), was significantly shorter for the complex patterns with regressions than for those without (see Table 7). The simple viewing patterns were associated with significantly longer gaze durations than both types of complex viewing patterns. This is in line with

\section{TABLE 6}

Mean durations of the first gaze at the target object, mean viewing times of the target object, mean total viewing times and reaction times obtained for each viewing pattern

\begin{tabular}{cccc}
\hline & $\begin{array}{c}\text { Complex pattern } \\
\text { without regression }\end{array}$ & $\begin{array}{c}\text { Complex pattern with } \\
\text { one/two regressions }\end{array}$ & $\begin{array}{c}\text { Simple } \\
\text { pattern }\end{array}$ \\
\hline VT1(T) & & & \\
$M$ & 284 & 262 & 447 \\
SD & 118 & 108 & 233 \\
VT(T) & & & \\
$M$ & 284 & 484 & 447 \\
SD & 118 & 211 & 233 \\
VTtot & & & \\
$M$ & 582 & 772 & 447 \\
SD & 199 & 254 & 233 \\
RT & & & \\
$M$ & 774 & 915 & 789 \\
SD & 218 & 234 & 244 \\
\hline
\end{tabular}




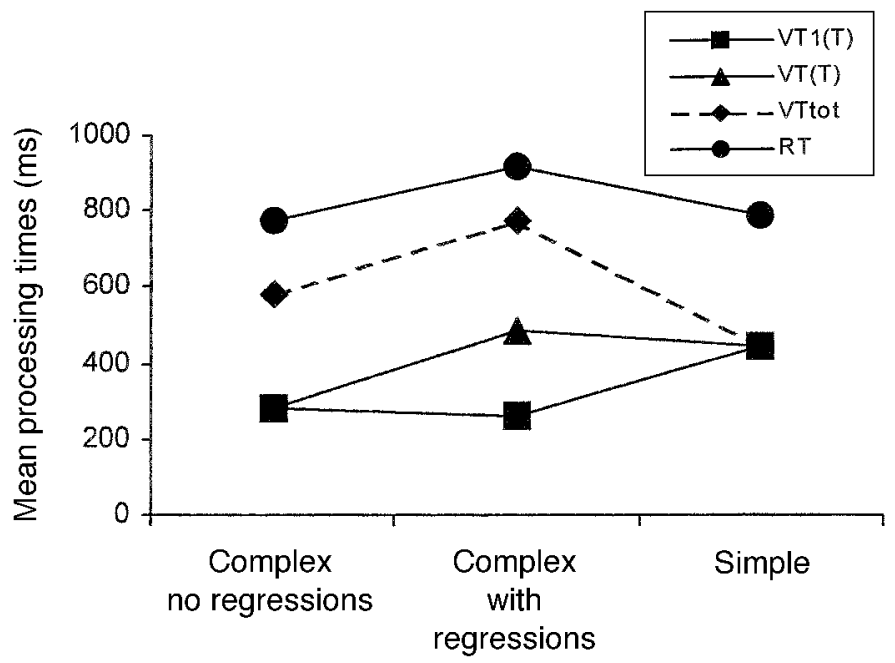

Viewing pattern

Figure 2. Mean values for the respective variables VT1(T), VT(T), VTtot, and RT, displayed for each viewing pattern. Dashed lines for VTtot indicate that VTtot is no direct measure of processing time but represents the sum of $\operatorname{VT}(\mathrm{T})$ and $\mathrm{VT}(\mathrm{C})$. Note that VT1(T) and VT(T) are identical for complex patterns without regressions, as well as VT1(T), VT(T), and VTtot being identical for simple viewing patterns.

TABLE 7

Paired comparisons between viewing patterns for the duration of the first gaze at the target object, the viewing time of the target object, total viewing time and reaction time

\begin{tabular}{|c|c|c|c|c|c|c|}
\hline & \multicolumn{2}{|c|}{$\begin{array}{l}\text { Pattern without regression } \\
\text { vs pattern with regression }\end{array}$} & \multicolumn{2}{|c|}{$\begin{array}{c}\text { Pattern without regression } \\
\text { vs simple pattern }\end{array}$} & \multicolumn{2}{|c|}{$\begin{array}{c}\text { Pattern with regression } \\
\text { vs simple pattern }\end{array}$} \\
\hline & $t 1^{a}$ & $t 2^{b}$ & $t 1^{a}$ & $t 2^{b}$ & $t 1^{a}$ & $t 2^{b}$ \\
\hline VT1(T) & $2.90 *$ & $2.12^{*}$ & $6.06 * * *$ & $7.51 * * *$ & $6.26 * * *$ & $7.64 * * *$ \\
\hline $\mathrm{VT}(\mathrm{T})$ & $12.94 * * *$ & $16.13 * * *$ & $6.06^{* * *}$ & $7.51 * * *$ & 1.89 & $2.65^{*}$ \\
\hline VTtot & $6.81 * * *$ & $11.68 * * *$ & $6.43 * * *$ & $9.76 * * *$ & $12.03 * * *$ & $15.27 * * *$ \\
\hline RT & $8.54 * * *$ & $7.46^{* * * *}$ & 0.73 & 0.65 & $5.43 * * *$ & $4.37 * * *$ \\
\hline
\end{tabular}

${ }^{\mathrm{a}} d f=15 .{ }^{\mathrm{b}} d f=135 .{ }^{*} p<.05 ; * * p<.01 ; * * * p<.001$. 
our assumption that the gaze durations should become shorter with increasing complexity and extensiveness of the viewing pattern. The overall viewing time of the target object, VT(T), was significantly longer for simple patterns than for complex patterns without regression. At the same time, however, VT(T) was significantly longer for complex patterns with regressions than for those without. This is obviously due to the fact that for complex patterns with regressions $\mathrm{VT}(\mathrm{T})$ includes the durations of the first gaze at the target object and all regressions to it. In sum, the analyses of the first gaze at the target object and its overall viewing time support the notion of structural differences between viewing patterns: The duration of the first gaze at the target became shorter the more explicit the viewing patterns got. This effect might occur because the very short first gazes at the target object were often too short to complete the processing such that participants had to return to the target object later to extract all the information that they need. However, it may also be an effect of preplanning with regard to the complexity and extensiveness of the overall viewing pattern to follow.

The longest reaction times and total viewing times were associated with the complex viewing patterns with regressions and the shortest with the simple viewing patterns (see Table 6 and Figure 2). However, the difference between the reaction times obtained for simple patterns as opposed to those for complex patterns without regression did not reach significance (see Table 7). The finding that complex viewing patterns without regressions and simple patterns did not differ in total reaction times is interesting with respect to the idea of an early response generation based on partial output of visual processing (Miller, 1982), as it implies that the time between the end of the extraction of visual information from the display and the button press was longer for the simple viewing patterns than for the complex viewing patterns, being associated with glances at both objects (see also Figure 2). This suggests that when using the complex viewing pattern without regressions the participants benefited from the additional information extracted during the longer and more thorough exploration of the display. When finishing the exploration process they were ready to press the correct buttons. There is one caveat, however, that should be kept in mind when interpreting this pattern of result in terms of early response generation: The time between the end of the total viewing time and the reaction time coincided with the beginning of the processing of the second task. Subjects were told to first do the "same"-" "different" decision and to then decide whether the symbol at the bottom of the screen was a plus or a cross. The earlier subjects had come to a decision with regard to the "same"-"different" judgement the earlier they started to process the second task. If they had not pressed the button yet, the second task might interfere with the first one and might thereby cause longer latencies between the end of the exploration of the object display and the button press. 


\section{DISCUSSION}

In spite of the wide range of experiments on "same"-" "different" judgements, these investigations seem to be rather abstract and without direct reference to the everyday relevance of multidimensional stimulus discrimination. Beyond visual perception, however, there are complex cognitive abilities that rely on the ability to decide whether two multidimensional stimuli are identical or not. In the following, we will first discuss the present findings in view of the research on "same"-"different" judgements and will then extrapolate the findings to account for overspecifications in referential noun phrase descriptions.

\section{Temporal and structural characteristics of multidimensional stimulus discrimination}

The present findings provide evidence from both viewing patterns and processing times in support of the hypothesis that conjunctive "same"-" different" decisions on two objects are made through parallel self-terminating processes. Participants looked for differences as long as necessary to detect one and checked the dimensions exhaustively only if the stimuli were identical. Thus, for multidimensional stimuli, decision times as well as viewing times and viewing patterns were determined by the difference dimension that was easiest to detect (self-terminating search). Ease of detection is closely connected to codability: Differences in absolute and highly codable dimensions, such as colour or object class, were detected faster than differences in size as a relative dimension. Note, however, that the effects of codability may be confounded with discriminability effects. The comparison of colour and object class differences did not reveal any effects of colour vs form processing. What seemed to be relevant for the decision process was the absoluteness of the object class difference and not the fact that it was a difference in form or colour. The relative processing times registered for same as opposed to different object pairs support the notion of a parallel processing mode. In the following, we will outline the use of these findings in view of experimental findings on the referential communication paradigm.

\section{Relevance of multidimensional stimulus discrimination on higher-order processes}

In the referential communication task, which shall serve here as an example of higher-order processes that rely on multidimensional stimulus discrimination, speakers have to refer to multidimensional objects in the context of other multidimensional objects by specifying a set of features that clearly distinguish the intended object from the surrounding objects (Eikmeyer \& Ahlsén, 1998; Eikmeyer, Schade, Kupietz, \& Laubenstein, 1999; Ford \& Olson, 1975; Herrmann \& Deutsch, 1976; Mangold-Allwinn, Baratelli, Kiefer, \& Koelbing, 1995; 
Pechmann, 1989, 1994; Schriefers \& Pechmann, 1988). In situated referential communication, multidimensionality means variation between objects in terms of dimensions such as colour, size, and object class in most of the cases (Danks \& Schwenk, 1972; Eikmeyer \& Ahlsén, 1998; Ford \& Olson, 1975; Olson, 1970; Pechmann, 1989; Whitehurst, 1976). Whitehurst (1976) found a strong tendency for children to produce more redundant utterances the older they get. Parallel investigations with adults also showed high frequencies of referential overspecifications: Speakers often utter features of the object to be specified that are redundant in view of a minimally contrastive specification (Eikmeyer \& Ahlsén, 1998; Herrmann \& Deutsch, 1976; Pechmann, 1989; Schriefers \& Pechmann, 1988). Following Whitehurst, we argue that it is the availability of features that determines the form of an object specification: "While contrastive descriptions are efficient in terms of words they may be inefficient in terms of the effort to appropriately analyze the stimulus array" (1976, p. 478). We assume that the analysis of distinctive features in a referential communication task can be reduced to multiple "same"'-“different" decisions and we will account for the high frequency of overspecifications in referential communication on the basis of the self-terminating search effect and the codability effect obtained in the present experiment and on the basis of the incrementality of speech production processes (Pechmann, 1989; Schriefers \& Pechmann, 1988).

We consider the case of minimal specifications first. Here, the process of referring minimally to an object in a referential communication task can be reduced to three main stages of the production process: (1) detecting differences between target object and context object(s), (2) evaluating detected differences with regard to their distinctiveness, and (3) verbalising the distinctive features by means of a complex noun phrase, e.g., "the large green lamp". The "same"-" "different" experiment presented earlier revealed the main characteristics of the first stage. We also know much about how speech production processes work and how the verbalisation stage might be modelled (Bock \& Levelt, 1994; Dell, 1986; Eikmeyer et al., 1999; Levelt, 1989; Levelt, Roelofs, \& Meyer, 1999; Schade, 1999). But what about the evaluation of stimulus dimensions with regard to their relevance?

A review of the literature on "same"'-"different" judgements shows that there are a number of investigations on the processes involved in making "same"'-"different"' decisions on one dimension while disregarding a second dimension (Ballesteros \& Manga, 1996; Besner \& Coltheart, 1976; Bundesen \& Larsen, 1975; Dixon \& Just, 1978; Jolicoeur \& Besner, 1987; Krueger, 1978; Miller \& Bauer, 1981; Sekuler \& Nash, 1972; Watanabe, 1988b). In order to model the processes underlying such complex decision tasks, Krueger (1978) developed the "noisy-operator theory", and Miller and Bauer (1981) developed the "relevance rechecking model", which was modified by Watanabe (1988b). These models all assume two basic stages: The first serves for difference detection only, whereas the second involves decisions on the relative relevance 
of the detected features. Krueger and Watanabe assumed that during the first stage, some irrelevant features could be filtered out, though not all. Whereas Krueger explained the insufficient early filtering on the basis of noise, Watanabe presented a more detailed analysis of the mechanisms involved. He investigated the influence of the relation between relevant and irrelevant stimulus dimensions in terms of their relative degree of integrality (Garner, 1974; Garner \& Felfoldy, 1970; Lockhead, 1972; Watanabe, 1988a, b). In two highly integral dimensions, such as orientation and form, the irrelevant dimension exerts a strong influence on the judgement of the relevant dimension. In contrast, two dimensions with a low degree of integrality (separable dimensions, e.g., colour and form) can easily be attended to selectively and judged independently of each other. In his experiments, Watanabe (1988a, b) found low degrees of integrality for colour and size and for colour and form, but high degrees of integrality for orientation and size. He specified the relevance rechecking model by Miller and Bauer as follows: If the dimensions involved in a "same"-" "different" decision task with one relevant and one irrelevant dimension are separable, "the information coming from this irrelevant dimension should be filtered out at the first stage", (1988b, p. 141).

The (modified) relevance rechecking model can be used to derive predictions on the availability of stimulus dimensions for the description of a multidimensional target object in the context of other multidimensional objects. Note, however, that, in the experiments cited previously on the effect of irrelevant differences on "same"'-"different" judgements of relevant dimensions, subjects were explicitly instructed which dimension to disregard. For the production of minimal specifications of multidimensional objects in a referential communication task, the evaluation of relevant vs irrelevant dimensions is part of the naming task. Taking into account Watanabe's (1988a, b) findings, together with the self-terminating search effect and the large impact of codability on the results of the present experiment on "same"-_"different"' decisions, we derived the following hypotheses:

Hypothesis 1. Differences in relative dimensions, such as size, that co-occur with differences in absolute dimensions, such as colour or object class, should be filtered out at the first stage. After being filtered, these dimensions are-as we will term it-functionally invisible in view of higher order processes. Note, however, that they are-in principle—visible and perceivable.

Hypothesis 2. Differences in absolute dimensions have to be rechecked at the second stage with regard to their relevance.

In view of experiments on referential communication, minimal specifications can be produced only on the basis of both stages within the relevance rechecking model. This implies rather large cognitive effort. Although a minimal specification would fulfil basic communication rules, such as Grice's (1975) maxim to 
be minimal, it is usually not necessary to produce minimal specifications but to produce unambiguous specifications. Thus, hypothesis 2 can be modified as follows:

Hypothesis 2a. It may cost less effort to specify irrelevant differences in absolute dimensions than to explicitly ignore them ("principle of least effort", "economy principle"; cf., Pechmann, 1994; Whitehurst, 1976).

Based on hypotheses 1 and 2a, we predicted that overspecifications of size as a relative dimension should occur rather seldomly, whereas colour as an absolute dimension should be overspecified more frequently.

Previous experiments had shown precisely this pattern of results (cf., Eikmeyer \& Ahlsén, 1998, for a review); however, these experiments provide only little evidence on the procedural origin of referential overspecifications. For a more exact assessment of the relation between the processes of detection and naming we ran a naming experiment on the basis of the stimulus material used in the "same"-" different" decision task. Eighteen participants who had not attended the detection experiment were asked to name the target object such that a listener could identify it in the display. The target object was marked by the preceding fixation point. The whole set of items of the detection task was used, including the same items. Participants were asked to say "same" if the two objects were identical and to name the target object when the objects differed. The plus/cross decision task was now carried out using a pushbutton panel to avoid interference between the naming task and the plus/cross decision task. As Table 8 shows, colour was overspecified substantially more often than size. Colour was also overspecified when it was merely present, but not varied between the objects (conditions $\mathrm{S}, \mathrm{O}, \mathrm{SO}$ ). However, the presence of an irrelevant difference in colour in conditions $\mathrm{CO}$ and SCO led to substantially higher rates of overspecifications of about $80 \%$ compared to the conditions without irrelevant colour variation (cf., Table 8). The comparison of $\mathrm{C}$ and $\mathrm{CO}$ with regard to the frequencies of colour overspecifications revealed a significant difference, $F(1,17)=8.74, p<.001$. Size, in contrast, was hardly ever overspecified. In condition CS, when minimal specifications included either colour or size, colour was specified more often than size (CO: 128 utterances; SO: 17 utterances). A Wilcoxon Signed Ranks Test for related samples showed that this difference was highly significant, $p=.00016, T^{+}=152, z=3.57, N=18$; because of the sample size $(N>15)$ the sum of ranks was transformed to a $z$ value (cf., Siegel \& Castellan, 1988).

In sum, these findings support the hypotheses developed here on the basis of the relevance rechecking model and the principle of "least effort": Size-differences, co-occurring with differences in absolute dimensions, such as colour or object class, are filtered out early during the detection process and are thus functionally invisible in view of the formulation process. The relative detectability of colour as opposed to size differences directly influences the selection 
TABLE 8

Percentages of specification types and overspecifications for each difference type (D-type)

\begin{tabular}{|c|c|c|c|c|c|c|}
\hline \multirow{3}{*}{ D-type } & \multirow{3}{*}{ Minimal specification } & \multirow{3}{*}{ Example } & \multicolumn{4}{|c|}{ Specification types (\%) } \\
\hline & & & \multirow[t]{2}{*}{ Minimal } & \multicolumn{3}{|c|}{ Overspecifications } \\
\hline & & & & $C$ & $S$ & $C \& S$ \\
\hline $\mathrm{C}$ & the black ball & & 100.0 & - & - & - \\
\hline $\mathrm{S}$ & the large ball & & 61.8 & 38.2 & - & - \\
\hline $\mathrm{O}$ & the ball & & 33.5 & 66.5 & - & - \\
\hline $\mathrm{CO}$ & the ball & & 19.8 & 80.2 & - & - \\
\hline $\mathrm{CS}$ & $\begin{array}{l}\text { the black ball } \\
\text { the small ball }\end{array}$ & & $\begin{array}{r}68.1 \\
9.0\end{array}$ & \multicolumn{2}{|c|}{22.9} & - \\
\hline $\mathrm{SO}$ & the ball & $x$ & 30.7 & 59.8 & 2.0 & 6.5 \\
\hline $\mathrm{CSO}$ & the ball & ts & 20.1 & 74.3 & 0.2 & 5.4 \\
\hline
\end{tabular}

of prenominal adjectives and thus determines largely the form of the object specifications. The filter mechanisms for size and colour are based on purely perceptual effects, i.e., the formation of referential overspecifications originates on the level of visual perception.

Pechmann (1989, 1994) and Schriefers and Pechmann (1988) stressed the importance of the incremental character of speech production processes. If speakers always waited for the results of a complex evaluation of all dimensions with regard to their relevance for a minimal object specification, they would have to postpone the initiation of speech production processes, too. Thus, by planning and producing their utterances incrementally, speakers are able to initiate articulation processes earlier and to thereby produce fluent utterances. Pechmann (1989) suggested that speakers use colour as an absolute dimension strategically: As soon as the first piece of information is available, linguistic encoding processes are initiated, while the relevant contextual alternatives are inspected in more detail. Thus, it is "characteristic of such a strategy that the speaker articulates features of the target before he has determined whether they are distinguishing or not" (Pechmann, 1989, p. 98).

\section{CONCLUSION}

The results presented in this paper provide answers to several open issues in the research on "same"-" different" decisions, such as the relation between processing times for same vs different stimuli and the procedural mechanisms that 
underlie the decision process and determine the decision times. On-line eyemovement measurements have proved not only a valuable tool to track the time course of "same"-_different" decision processes but also supportive of current model-based approaches to "same" -“different" judgements. Beyond a consideration of the present findings in the context of the state of the art of the research on "same"'-"different", judgements conducted so far, we gave an example of how the data can be integrated in a more general framework of research on higher-order processes. On the basis of a parallel assessment of the stimulus material in the detection task and in a referential communication task we argued that the results obtained in experiments on naming multidimensional stimuli are largely dependent on perceptual processes involved in "same" "different" decisions. Beyond this strong perceptual influence, the incremental character of speech production processes seems to be an important determinant of the form of object specifications.

Manuscript received July 2000

Revised manuscript received February 2001

\section{REFERENCES}

Allport, D.A. (1971). Parallel encoding within and between elementary stimulus dimensions. Perception and Psychophysics, 10(2), 104-108.

Ballesteros, S., \& Manga, D. (1996). The effect of variation of an irrelevant dimension on samedifferent visual judgments. Acta Psychologica, 92, 1-16.

Bamber, D. (1969). Reaction times and error rates for "same'”-“different" judgments of multidimensional stimuli. Perception and Psychophysics, 6(3), 169-174.

Besner, D., \& Coltheart, M. (1976). Mental size scaling examined. Memory and Cognition, 4(5), $525-531$.

Bindra, D., Donderi, D.C., \& Nishisato, S. (1968). Decision latencies of "same" and "different" judgments. Perception and Psychophysics, 3(2B), 121-130.

Bock, K., \& Levelt, W.J.M. (1994). Grammatical encoding. In S.A. Gernsbacher (Ed.), Handbook of psycholinguistics (pp. 945-984). New York: Academic Press.

Boucart, M., \& Humphreys, G.W. (1992). Global shape cannot be attended without object identification. Journal of Experimental Psychology: Human Perception and Performance, 18(3), 785806.

Boucart, M., \& Humphreys, G.W. (1994). Attention to orientation, size, luminance, and color: Attentional failure within the form domain. Journal of Experimental Psychology: Human Perception and Performance, 20(1), 61-80.

Boucart, M., \& Humphreys, G.W. (1997). Selection by color and form in vision. Journal of Experimental Psychology: Human Perception and Performance, 23(1), 136-153.

Brunel, N., \& Ninio, J. (1997). Time to detect the difference between two images presented side by side. Cognitive Brain Research, 5, 273-282.

Bundesen, C., \& Larsen, A. (1975). Visual transformation of size. Journal of Experimental Psychology: Human Perception and Performance, 1(3), 214-220.

Carlson-Radvansky, L.A., \& Irwin, D.E. (1995). Memory for structural information across eye movements. Journal of Experimental Psychology: Learning, Memory, and Cognition, 21(6), 1441-1458. 
Clark, H.H. (1973). The language-as-fixed-effect fallacy: A critique of language statistics in psychological research. Journal of Verbal Learning and Verbal Behavior, 12, 335-359.

Coltheart, M. (1980). Iconic memory and visual persistence. Perception and Psychophysic s, 27, 138227.

Danks, J.H., \& Schwenk, M.A. (1972). Prenominal adjective order and communication context. Journal of Verbal Learning and Verbal Behavior, 11, 183-187.

Dell, G.S. (1986). A spreading activation theory of retrieval in sentence production. Psychological Review, 93, 283-321.

Deubel, H., \& Schneider, W.X. (1996). Saccade selection and object recognition: Evidence for a common attentional mechanism. Vision Research, 30, 1827-1837.

Dixon, P., \& Just, M.A. (1978). Normalization of irrelevant dimensions in stimulus comparisons. Journal of Experimental Psychology: Human Perception and Performance, 4(1), 36-46.

Donderi, D., \& Case, B. (1970). Parallel visual processing: Constant same-different decision latency with two to fourteen shapes. Perception and Psychophysics, 8(5B), 373-375.

Donderi, D., \& Zelnicker, D. (1969). Parallel processing in visual same-different decisions. Perception and Psychophysics, 5(4), 197-200.

Downing, B.D. (1970). Response probabilities and "same-different" reaction times. Perception and Psychophysics, 9(2B), 213-215.

Downing, B.D., \& Gossman, J.R. (1970). Parallel processing of multidimensional stimuli. Perception and Psychophysics, 8(1), 57-60.

Egeth, H.E. (1966). Parallel vs. serial processes in multidimensional stimulus discrimination. Perception and Psychophysics, 1, 245-252.

Eikmeyer, H.-J., \& Ahlsén, E. (1998). The cognitive process of referring to an object: A comparative study of German and Swedish. In T. Haukioja (Ed.), Papers from the 16th Scandinavian conference of Linguistics (Vol. 60, pp. 75-86). Turku, Finland: Department of Finnish and General Linguistics, University of Turku.

Eikmeyer, H.-J., Schade, U., Kupietz, M., \& Laubenstein, U. (1999). A connectionist view of language production. In R. Klabunde \& C. von Stutterheim (Eds.), Representations and processes in language production (pp. 205-236). Wiesbaden, Germany: Deutscher Universitäts-Verlag.

Entus A., \& Bindra, D. (1970). Common features of the "repetition"' and "same-different" effects in reaction time experiments. Perception and Psychophysics, 7(3), 143-148.

Farell, B. (1985). "Same”-“different'” judgments: A review of current controversies in perceptual comparisons. Psychological Bulletin, 98(3), 419-456.

Ford, W., \& Olson, D. (1975). The elaboration of the noun phrase in children's description of objects. Journal of Experimental Child Psychology, 19, 371-382.

Garner, W.R. (1974). The processing of information and structure. Potomac, MD: Lawrence Erlbaum Associates, Inc.

Garner, W.R., \& Felfoldy, G.L. (1970). Integrality of stimulus dimensions in various types of information processing. Cognitive Psychology, 1, 225-241.

Grice, H.P. (1975). Logic and conversation. In P. Cole \& J. Morgan (Eds.), Speech acts (pp. 41-58). New York: Academic Press.

Grill, D.P. (1971). Variables influencing the mode of processing of complex stimuli. Perception and Psychophysics, 10(1), 51-57.

Hawkins, H.L. (1969). Parallel processing in complex visual discrimination. Perception and Psychophysics, 5(1), 56-64.

Henderson, J.M., Pollatsek, A., \& Rayner, K. (1987). Effects of foveal priming and extrafoveal preview on object identification. Journal of Experimental Psychology: Learning, Memory, and Cognition, 13(3), 449-463.

Henderson, J.M., Pollatsek, A., \& Rayner, K. (1989). Covert visual attention and extrafoveal information use during object identification. Perception and Psychophysics, 45(3), 196-208. 
Herrmann, T., \& Deutsch, W. (1976). Psychologie der Objektbenennung [Psychology of object naming]. Bern, Switzerland: Huber.

Irwin, D.E. (1991). Information integration across saccadic eye movements. Cognitive Psychology, $23,420-456$.

Irwin, D.E. (1992). Visual memory within and across fixations. In K. Rayner (Ed.), Eye movements and visual cognition: Scene perception and reading (pp. 146-165). New York: Springer.

Jolicoeur, P., \& Besner, D. (1987). Additivity and interaction between size ratio and response category in the comparison of size-discrepant shapes. Journal of Experimental Psychology: Human Perception and Performance, 13(3), 478-487.

Just, M.A., \& Carpenter, P.A. (1980). A theory of reading: From eye fixations to comprehension . Psychological Review, 87, 329-354.

Krueger, L.E. (1973). Effect of stimulus frequency on speed of "same"_-“different" judgments. In S. Kornblum (Ed.), Attention and performance IV (pp. 497-506). New York: Academic Press.

Krueger, L.E. (1978). A theory of perceptual matching. Psychological Review, 85(4), 278-304.

Larsen, A., \& Bundesen, C. (1978). Size scaling in visual pattern recognition. Journal of Experimental Psychology: Human Perception and Performance, 4(1), 1-20.

Levelt, W.J.M. (1989). Speaking: From intention to articulation. Cambridge, MA: MIT Press.

Levelt, W.J.M., Roelofs, A., \& Meyer, A.S. (1999). A theory of lexical access in speech production. Behavioral and Brain Sciences, 22(1), 1-75.

Lindsay, R.K., \& Lindsay, J.M. (1966). Reaction time and serial versus parallel information processing. Journal of Experimental Psychology, 71(2), 294-303.

Lockhead, G.R. (1972). Processing dimensional stimuli: A note. Psychological Review, 79(5), 410419.

Mangold-Allwinn, R., Baratelli, S., Kiefer, M., \& Koelbing, H.G. (1995). Wörter für Dinge: Von flexiblen Konzepten zu variablen Objektbenennungen [Words for things: From flexible concepts to variable object names]. Opladen, Germany: Westdeutscher Verlag.

Mannhaupt, H.-R. (1983). Produktionsnormen für verbale Reaktionen zu 40 geläufigen Kategorien. Sprache und Kognition, 4, 264-268.

Meyer, A.S., Sleiderink, A., \& Levelt, W.J.M. (1998). Viewing and naming objects: Eye movements during noun phrase production. Cognition, 66, B25-B33.

Meyer, A.S., \& van der Meulen, F.F. (2000). Phonological priming effects on speech onset latencies and viewing times in object naming. Psychonomic Bulletin and Review, 7(2), 314-319.

Miller, G.O., \& Bauer, D.W. (1981). Irrelevant differences in the "same",-“different"' task. Journal of Experimental Psychology: Human Perception and Performance, 7, 196-207.

Miller, J. (1978). Multidimensional same-different judgments: Evidence against independent comparisons of dimensions. Journal of Experimental Psychology: Human Perception and Performance, 4(3), 411-422.

Miller, J. (1982). Discrete versus continuous stage models of human information processing: In search of partial output. Journal of Experimental Psychology: Human Perception and Performance, 8(2), 273-296.

Nickerson, R.S. (1965). Response times for "same"'-“different"” judgments. Perceptual and Motor Skills, 20, 15-18.

Nickerson, R.S. (1967). "Same”-“different", response times with multi-attribute stimulus differences. Perceptual and Motor Skills, 24, 543-554.

Nickerson, R.S. (1969). "Same"'-“different”' response times: A model and a preliminary test. Acta Psychologica, 30, 257-275.

Nickerson, R.S. (1971). "Same"'-“different", response times: A further test and a "counter and clock" model. Acta Psychologica, 35, 112-127.

Nickerson, R.S. (1972). Binary-classification of reaction time: A review of some studies of human information-processing capabilities. Psychonomic Monograph Supplement, 4(17), 275-318. 
Nickerson, R.S. (1973). Frequency, recency, and repetition effects on same and different response times. Journal of Experimental Psychology, 101(2), 330-336.

Olson, D.R. (1970). Language and thought: Aspects of a cognitive theory of semantics. Psychological Review, 77(4), 257-273.

Pechmann, T. (1989). Incremental speech production and referential overspecification. Linguistics, 27, 89-110.

Pechmann, T. (1994). Sprachproduktion: Zur Generierung komplexer Nominalphrasen [Speech production: On the generation of complex noun phrases]. Opladen, Germany: Westdeutscher Verlag.

Piaget, J. (1926). The language and thought of the child. New York: Harcourt Brace.

Posner, M.I. (1980). Orienting of attention. Quarterly Journal of Experimental Psychology, 32, 3-25.

Raaijmakers, J.G.W., Schrijnemakers, J.M.C., \& Gremmen, F. (1999). How to deal with "the language-as-fixed-effect fallacy' ': Common misconceptions and alternative solutions. Journal of Memory and Language, 41, 416-426.

Rayner, K. (1998). Eye movements in reading and information processing: 20 years of research. Psychological Bulletin, 124(3), 372-422.

Santee, J.L., \& Egeth, H.E. (1980). Selective attention in the speeded classification and comparison of multidimensional stimuli. Perception and Psychophysics, 28(3), 191-204.

Schade, U. (1999). Konnektionistische Sprachproduktion [Connectionist speech production]. Wiesbaden, Germany: Deutscher Universitäts-Verlag.

Schriefers, H., \& Pechmann, T. (1988). Incremental production of referential noun-phrase s by human speakers. In M. Zock \& G. Sabah (Eds.), Advances in natural language generation (pp. 172179). London: Pinter.

Sekuler, R., \& Nash, D. (1972). Speed of size scaling in human vision. Psychonomic Science, 27(2), 93-94.

Siegel, S., \& Castellan, N.J. (1988). Nonparametric tests for the behavioral sciences. New York: McGraw-Hill.

Snodgrass, J.G., \& Townsend, J.T. (1980). Comparing parallel and serial models: Theory and implementation. Journal of Experimental Psychology: Human Perception and Performance, 6(2), 330-334.

Snodgrass, J.G., \& Vanderwart, M. (1980). A standardized set of 260 pictures: Norms for name agreement, image agreement, familiarity and visual complexity. Journal of Experimental Psychology: Human Learning and Memory, 6, 174-215.

Tanenhaus, M.K., Spivey-Knowlton, M.J., Eberhard, K.M., \& Sedivy, J.C. (1995). Integration of visual and linguistic information in spoken language comprehension. Science, 268, 1632-1634.

Watanabe, T. (1988a). Effect of the amount of the irrelevant disparity on different reaction times. Japanese Psychological Research, 30(1), 11-17.

Watanabe, T. (1988b). Effect of irrelevant differences as a function of the relations between relevant and irrelevant dimensions in the same-different task. Journal of Experimental Psychology: Human Perception and Performance, 14(1), 132-142.

Whitehurst, G.J. (1976). The development of communication: Changes with age and modeling. Child Development, 47, 473-482.

Williams, J.D. (1972). Effects of practice with controlled stimulus pairs on same-different judgments. Journal of Experimental Psychology, 96, 73-77.

Winer, B.J. (1971). Statistical principles in experimental design. New York: McGraw-Hill.

Zelinsky, G., \& Sheinberg, D. (1995). Why some search tasks take longer than others: Using eye movements to redefine reaction times. In J.M. Findlay, R. Walker, \& R.W. Kentridge (Eds.), Eye movement research: Mechanisms, processes, and applications (pp. 325-336). Amsterdam: North Holland.

Zelinsky, G., \& Sheinberg, D. (1997). Eye movements during parallel-serial visual search. Journal of Experimental Psychology: Human Perception and Performance, 22(1), 244-262. 